\title{
Nachruf für Professor Dr. Otto Kimminich
}

Am 12. August 1997 verstarb Univ.-Professor Dr. jur. Otto Kimminich. Er war Verfassung und Recht in Übersee vom 3. bis zum 30. Jahrgang, vor allem aber in den vergangenen neun Jahren eng als engagierter Autor und Rezensent verbunden. In stets entgegenkommender Zusammenarbeit, auch durch ermutigende Resonanz hat er unsere Arbeit über viele Jahre hinweg mitgetragen.

Dies ist nicht der Ort, das Wirken von Professor Kimminich umfassend zu würdigen. Die Qualität und Vielzahl seiner wissenschaftlichen Veröffentlichungen sprechen eine deutliche Sprache. Einhellig ist die Bewunderung der Breite und Tiefe seiner Forschungen. Frühzeitig hat er sich mit heute gängigen Gegenwartsproblemen auseinandergesetzt, als das Ausmaß ihrer Bedeutung noch nicht jedem erkennbar war: Rüstung, Asylrecht, Völkerrecht im Atomzeitalter, Menschenrechte und humanitäres Völkerrecht, nicht zuletzt Umweltrecht jeweils durchaus auch bezogen auf die rechtliche und tatsächliche Lage in Übersee.

In Verfassung und Recht in Übersee untersuchte Professor Kimminich bereits im Jahre 1970 das humanitäre Völkerrecht anläßlich der Unterzeichnung der afrikanischen Flüchtlingskonvention (Der Schutz der politischen Flüchtlinge in Afrika. Ein Beitrag der jungen Staaten zur Entwicklung des humanitären Völkerrechts, VRÜ 3 (1970), S. 443 ff.). Er beklagte, in "dem Widerstreit zwischen Asylrecht und Staatsschutz (habe) sich auch in Afrika offensichtlich der letztere durchgesetzt", begrüßte jedoch insgesamt den "Schritt vorwärts in Richtung auf eine Betonung des Asylschutzes und der Rechte des einzelnen" (S. 459). Immer wieder rief Kimminich auf, die Menschenrechte als Kernstück der neuen Völkerrechtsordnung zu sehen und die friedensstiftende Wirkung der Menschenrechte nicht als bloße Phrase abzutun (Menschenrechte im Wandel des Staatsbegriffs und der Staatengemeinschaft, VRÜ 21 (1988), S. 416, 428). Der Beitrag endet mit der nüchternen Feststellung: "Die Menschenrechte sind Ziel und Mittel zugleich. Sie dienen dem Frieden und der Frieden dient ihnen" (S. 429).

Auch in seiner engagierten Rezensionstätigkeit für unsere Zeitschrift kehren solche Themen wieder. Mit Beharrlichkeit, Offenheit und erkennbarem Respekt für Meinungen anderer widmete sich Kimminich einer langen Reihe von Werken zu allgemeinen Grundfragen des Völkerrechts, zu den Menschenrechten, zum Minderheitenschutz und last but not least zur überseeischen Verfassungsvergleichung. Viele dieser Problemstellungen werden auch in seinem im Jahre 1986 in dieser Zeitschrift (S. 109) rezensierten Buch "Rechtsprobleme der polyethnischen Staatsorganisation. Entwicklung und Frieden" im Zusammenhang behandelt. Zuletzt wandte sich Professor Kimminich in diesem Jahrgang mit zwei Rezensionen 
"Hans Kelsens Völkerrechtslehre" von Alfred Rub (S. 80) sowie dem "Handbuch der Grund- und Menschenrechte auf staatlicher, europäischer und universeller Ebene" von Gerd Seidel (S. 255) zu.

Wir trauern um Professor Kimminich. Sein Engagement für die Zeitschrift und seine Handschrift werden uns sehr fehlen. Sein Gespür für die Verfassung und das Recht in Übersee wird uns unvergessen sein. Wir empfinden die Verpflichtung, auch in seinem Sinne die Dinge fortzuführen.

UlfMarzik 